\title{
Eu kitsch: uma análise da atitude kitsch na obra de Pedro Almodóvar
}

I kitsch: a analysis about the kitsch attitude in the work of Pedro Almodóvar

Hallina Beltrão, Hans Waechter

Kitsch, neokitsch, estética, cinema, Pedro Almodóvar.

Este artigo aborda o kitsch como fenômeno mundial estabelecido e identifica sua presença na obra de Pedro Almodóvar através da análise de Mulheres à beira de um ataque de nervos (1987), Ata-me (1989) e Kika (1993), três películas da fase mais kitsch do diretor espanhol.

Kitsch, neokitsch, aesthetics, cinema, Pedro Almodóvar.

This article shows the kitsch as established world-wide phenomenon and identifies its presence in the work of Pedro Almodóvar through the analysis of Women on the verge of a nervous breakdown (1987), Tie me up! Tie me down! (1989) and Kika (1993), three of the most kitsch films by the spanish director.

\section{Introdução}

O trabalho do aclamado diretor Pedro Almodóvar carrega em si muitas particularidades que fizeram do espanhol único em sua arte. Seus filmes, super autobiográficos, lançam um olhar singular sobre o universo feminino e sempre trazem temas fortes e controversos.

Contudo, a discussão que gira em torno do cineasta vai além da temática, das cenas fortes e dos personagens pouco comuns. Há também em suas películas uma polêmica de origem estética que se chama kitsch. Durante muitos anos e dez longas metragens, o diretor foi atacado pela crítica por contar com a presença do kitsch na estética dos seus filmes.

Este artigo se propõe justamente a tornar claro o significado desse tal kitsch, conhecendo as múltiplas questões que o definem e procurando quebrar os preconceitos inerentes ao termo, com o propósito de, finalmente, analisar sua presença e importância na obra do diretor espanhol.

\section{Kitsch?}

O termo kitsch geralmente causa polêmica ao ser conceituado. O que para uns é a personificação do mau gosto, para outros é a prova do quanto o gosto popular pode ser autêntico. Não é uma estética, um movimento artístico ou um xingamento - como muitos usam de maneira equivocada quando querem depreciar algo.

A melhor definição que encontramos é a de Abraham Moles que diz que o kitsch é uma atitude. Atitude de uma sociedade diante dos seus objetos de consumo. Um estilo marcado pela ausência de estilo.

O kitsch é uma mistura divertida de vários elementos, geralmente com o único propósito de ornamentação. Sobrepõe materiais, estilos artísticos, cores e estampas de uma forma harmônica e irreverente. Nessa combinação, não existem regras. Vale misturar, no mesmo ambiente, anjinhos barrocos, cópias de quadros de Picasso, imagens de santos, bonequinhos de plástico e mais o que der na cabeça. É a idéia do "so-bad-it's-good" que faz do kitsch a arte da alegria e da embriaguez dos sentidos.

O vocábulo surgiu pela primeira vez em Munique, em 1860, para designar uma mercadoria ordinária, que geralmente tentava copiar toscamente uma original. Vem do alemão Kitschen, que quer dizer atravancar e, mais especificamente, fazer móveis novos com velhos. Ainda com o mesmo radical e sentido pejorativo, há a palavra vertkitschen (trapacear, receptar, vender outra 


\section{Infodesıgn}

mercadoria no lugar da que havia sido prometida). Para Ludwig Giesz, em Phänomenologie des Kitsches, o vocábulo derivaria de uma corruptela do termo inglês sketch, surgido na segunda metade do século XIX, quando turistas americanos compravam imitações de arte na Alemanha por preços irrisórios. A palavra, que se mantém intraduzível, conquistou o mundo, simbolizando um conceito universal.

A história do kitsch se divide basicamente em duas fases. A primeira remete à época da ascensão da burguesia, que, com as grandes navegações e a indústria manufaturada, conquistou uma posição privilegiada na sociedade. Cheios de dinheiro, os burgueses queriam possuir os objetos de arte que a aristocracia tanto ostentava, mas a um preço mais justo. Pintores e artesãos amadores eram contratados para reproduzir quadros, móveis, jóias e artigos de decoração usados pela nobreza. Nessa fase, cada objeto revestia-se de um grande valor sentimental. Era como se cada um fizesse parte da história do seu proprietário, que o conservava por toda a vida.

A segunda grande fase se inicia na década de 1920, impulsionada pelo surgimento das lojas gigantes. Os Estados Unidos, a Inglaterra e a França foram os primeiros países a se renderem ao encanto dos big magazines, que se tornaram verdadeiros templos do consumo e tinham em seus estoques vários artigos sem procedência específica, projetados por designers especialmente para agradar o público. É o neokitsch, período áureo do kitsch, que dura até hoje. Nele, as pessoas já não têm relação afetiva com os artigos comprados, consomem por consumir. Para o comprador de um produto neokitsch, a escolha entre uma imagem santa e uma Hello Kitty é aleatória, determinada por um impulso ou uma vaga idéia do que seria mais cômico ou incomum. Observando, por exemplo, a transição das formas de representação dos temas religiosos nos dois estilos, o primeiro fundamenta-se na crença religiosa, enquanto no segundo o objeto passa de sagrado a divertido, algo que é comprado por estar na moda.

\subsection{Nem tudo o que reluz é kitsch}

É muito fácil falar que tudo que é exagerado, misturando vários estilos e com um cisne rosa no meio, é kitsch. Mas não é tão simples, já que sua definição é relativa. Um objeto pode ser kitsch para uma sociedade e obra de arte para outra. Qualquer peça só deve ser considerada kitsch se o contexto no qual ela está inserida for analisado.

Para não deixar a conceituação livre de parâmetros ou referências, é preciso estabelecer as características gerais que um objeto ou grupo de objetos deve ter para ser kitsch, considerando, é claro, o seu contexto. Abraham Moles, em seu livro O kitsch (1971), através da chamada "tipologia do kitsch", conseguiu traçar um perfil bastante claro das propriedades que fazem um anão de jardim ou um quarto decorado com Barbies e lava lamps ser kitsch ou não.

Tipologia, no sentido proposto, é resultado do estudo dos diversos parâmetros econômicos, sociológicos ou psicológicos, somados à classificação do aparecimento de aspectos específicos como atitudes, valores e, ainda, a pesquisa estatística da moda em determinado momento.

A tipologia é aplicada a dois aspectos do kitsch: sobre peças isoladas, que por si só contêm toda uma carga da estética; e sobre grupos que, unidos num contexto específico, constituem um sistema kitsch, mesmo que ao serem vistos isoladamente não apresentem nenhum de seus sinais.

Os indicadores que definem a presença do kitsch em objetos são:

- desproporção das dimensões geométricas em relação ao objeto representado - os souvenirs geralmente são providos dessa característica;

- uso de símbolos religiosos na produção de objetos profanos, deturpados em seu sentido;

- uso de elementos eróticos - artigos com formatos sugestivos ou sadomasoquistas, como chicotes e algemas, por exemplo;

- objetos com acabamento grosseiro ou feitos com material ordinário.

No que se refere aos aspectos da tipologia, os objetos ou mensagens unitárias reúnem neles próprios as propriedades do kitsch em formas, cores, materiais e dimensões. Já os conjuntos de objetos constituem um sistema kitsch, mesmo que cada componente do grupo, quando isolado, não apresente as características propostas (fator de empilhamento).

\section{Tipologia das formas elementares}

De acordo com cada época, o kitsch recorre a determinadas formas, mas, em geral, as formas preferenciais seguem estas propriedades:

- curvas que se ligam umas às outras, de modo progressivo e contínuo, são exemplos do estilo macarrônico (que tem este nome por analogia às deformações e curvaturas que o 
macarrão sofre no seu cozimento) da entrada do metrô de Paris, uma das maiores obras da art nouveau, bem como as florações de curvaturas De Stijl - as curvas mencionadas são predominantes do início do século XX, quando esse estilo era a febre da sociedade de consumo;

- objetos, na maioria das vezes, dispostos em superfícies repletas de representações, símbolos ou adornos;

- cores que contrastam com branco, vermelho e rosa pink, as mais usadas, fazendo um dégradé até o lilás e o violeta. A combinação de todas as cores do arco-íris, misturadas ao máximo, no mesmo objeto ou na composição de um ambiente, também se faz presente. Trata-se de um "jogo duvidoso de cores", segundo o "bom gosto";

- materiais imitando outros materiais. Os elementos raramente se apresentam como tal. A madeira simula o mármore; o plástico, a porcelana; o tecido, uma pétala de flor; o bronze, o ouro. São disfarçados por verniz, pintura, gesso e tudo que possa, de acordo com o significado do termo kitsch, fazer uma mercadoria parecer-se com outra.

Tipologia dos grupos de objetos

A classificação analisa a relação entre as peças do agrupamento que, neste caso, vai determinar a presença do kitsch. São critérios do agrupamento:

- Critério de empilhamento: desde uma mesa, geladeira ou móvel, até o cenário de um filme, um cartaz, um folder, uma capa de livro ou de CD. Os itens são tantos para o ambiente que chegam a se tocar, disputando entre si o espaço. É a chamada "pressão kitsch";

- Critério da heterogeneidade: não há relação direta entre os elementos, o que algumas vezes pode gerar um surrealismo inconsciente;

- Critério de antifuncionalidade: ocorre um agrupamento espontâneo de objetos que, em si, não têm nenhuma função que o justifique;

- Critério de autenticidade kitsch: este critério diz respeito ao modo como cada objeto é adquirido. Um espaço kitsch geralmente não é finalizado de uma hora para outra. Cada peça adquirida constitui um troféu para o seu dono. São souvenirs dos lugares visitados, símbolos de uma ascensão social ou econômica que têm uma ligação profundamente emocional com seu dono. É a construção de lembranças de uma vida.

Os critérios propostos pela tipologia não identificam automaticamente um objeto como kitsch, embora a presença de três ou mais desses indicadores seja determinante nesta análise.

Em um ambiente kitsch, geralmente surgem, entre os signos, várias oposições dialéticas. Um Elvis Presley vestido de anjo (religioso versus profano), um cacto de plástico ao lado de gatinhos de porcelana (exótico versus comum), uma estátua de deusa grega nua junto com uma Hello Kitty (erótico versus familiar), um abajur de estilo art nouveau e miniaturas de foguetes (tradicional versus futurista).

Essa é a descrição de um típico espaço kitsch, que com tais combinações entre objetos de significados opostos - e por que não surreais? - tem o poder de despertar diversos estímulos emotivos e perceptivos. Essas combinações são feitas sem preconceitos, sem medo de pecar, e é justamente essa multiplicidade que enriquece o kitsch. Ele encontra sua harmonia ignorando $o$ bom ou mau gosto, o esteticamente correto. Isto faz com que passe pelos anos ileso às críticas que o execram.

\subsection{O "kitsch-kitsch"}

A segunda fase do kitsch, ou neokitsch, surgiu em meados de 1930, nos Estados unidos, em conseqüência do nascimento de um novo sistema econômico, denominado pelo termo simbólico de "Lojas Americanas". Lojas imensas e muito iluminadas, que vendiam os mais diversos produtos dispostos em vitrines e displays, a um preço fixo acessível, de modo que despertassem o máximo desejo do consumidor.

O neokitsch tinha fortes características americanas, pelas suas origens, e seduzia as pessoas pelo design dos produtos. O 'novo' kitsch não se baseava em modelos do passado, como o 'velho'. O designer, profissão nova na época, traduzia nas formas dos objetos a vontade do público, sempre com um toque de inovação.

O maior critério de distinção entre o kitsch e o neokitsch é a substituição do objeto proposta pelo novo estilo. Não havia mais o valor sentimental atribuído ao produto, como acontecia no 
kitsch. A ausência do sentimento faz do objeto um ícone vazio, cujo valor se sustenta principalmente no seu caráter de ícone, que está acima do fato de ser um bem material. $\mathrm{O}$ neokitsch é a sua própria referência, o "kitsch-kitsch".

Do ponto de vista histórico, o neokitsch explode numa época em que o mundo (principalmente os Estados Unidos, que haviam passado pela crise de 1929 e por duas guerras mundiais) queria esquecer os tempos difíceis jogando-se na euforia do consumo. $E$ foi nesse período marcado pelo fim dos anos 40 e o início dos 50 que ele entrou em fase de ascensão meteórica. Era a idade dos drive-ins, dos eletrodomésticos supercoloridos, dos carros rabo-de-peixe. Depois de tantas dificuldades, uma overdose de glamour.

A partir dessa época, a relação entre a sociedade de consumo e os bens adquiridos sofreu uma grande mudança. Os produtos que antes eram feitos para durar uma vida, agora tinham tempo programado de uso e substituição. Tudo de repente tornou-se descartável. Ainda que estivessem funcionando bem, sempre apareciam os defeitinhos já previstos pelo designer ou era criado um modelo com design mais avançado, o que obrigava a população, ansiosa por novidade, a substituir o produto antigo. Carros, eletrodomésticos, móveis e roupas passaram a ter uma obsolescência 'programada' dentro de um sistema que só dava valor ao novo: "Tratava-se de uma ética do supérfluo, da extinção planejada e do consumo forçado" (Moles, 1971, p.167); "A lógica econômica realmente varreu todo ideal de permanência, é a regra do efêmero que governa a produção e o consumo dos objetos" (Lipovetsky, 1989, p.160).

Em busca da inovação necessária, as empresas se aliam à ciência, ao design e à publicidade $e$ apostam suas fichas no aperfeiçoamento dos produtos. Às vezes ocorre a mudança de pequenos detalhes no design ou o aumento no número de funções, o que pode fazer o consumidor considerar seu aparelho obsoleto, mesmo que funcione perfeitamente, e trocá-lo por um novo, mais 'moderno'.

A oferta e a procura funcionam pelo Novo; nosso sistema econômico é arrastado numa espiral onde a inovação grande ou pequena é rainha, onde o desuso se acelera: certos especialistas em marketing e em inovação podem assegurar que, em dez anos, 80 a 90 por cento dos produtos atuais estarão

desclassificados, serão apresentados sob uma forma nova e em nova embalagem. (Lipovetsky, 1989, p.160)

Essa nova lógica que impera na economia mundial até hoje, aliada às vendas a prazo, foi responsável por uma verdadeira explosão no comércio e, conseqüentemente, na indústria. Pela primeira vez na História, o operário assalariado podia gastar em carros, passeios, móveis e - por que não? - em futilidades, pagando tudo em prestações a perder de vista. O kitsch se instala de maneira definitiva na vida das pessoas.

\subsection{1. 'Arte de segunda-mão'?}

... o kitsch é mais uma direção do que um objetivo, dele todos fogem - Kitsch, é uma injúria artística mas todo mundo a ele retorna: o artista que faz concessões ao gosto do público, estimado de modo mais ou menos justo, o espectador que frui e aprecia ... Pitada de bom gosto na falta de gosto, pitada de arte na feiúra ... arte adaptada à vida e cuja função adaptativa ultrapassa a função inovadora... (Moles, 1971, p.28)

O kitsch indiscutivelmente perdeu a conotação de 'arte de segunda-mão' para tornar-se um fenômeno mundial, e há um fator determinante para esse boom. Se as Lojas Americanas foram fundamentais para o surgimento do neokitsch, numa escala de proporções, Hollywood foi a causa fundamental para sua permanência definitiva, não como sub-arte, mas como uma influência positiva na própria arte. Os filmes por si já alimentavam no público muitas fantasias, mas foi Hollywood que transformou seres humanos mortais em estrelas. Elvis Presley, Marilyn Monroe e muitos outros se tornaram mais que ídolos do cinema, verdadeiros ícones do kitsch.

Foram justamente ídolos como Marilyn e Elvis alguns dos principais instrumentos de trabalho de Andy Warhol, grande nome da pop art, que glorificava o consumismo americano em suas obras. O que foi a pop art senão a entrada do kitsch pela porta da frente da arte? Junto com Roy Lichtenstein, Richard Hamilton, Jasper Johns e Robert Indiana, Warhol criou o movimento artístico mais irreverente e democrático até então. A pop art transformava símbolos da cultura popular e objetos corriqueiros da vida cotidiana em obras de arte. Latas de sopa, garrafas de Coca-cola quadrinhos, ídolos do cinema e da música foram sua matéria-prima. O movimento, que povoou as décadas de 1950 e 1960, encarava com ironia o consumo massificado, mas, ao mesmo tempo, exaltava a cultura de massa, dando a elementos da cultura popular status de obra-prima. Enfim, a democracia da arte. 
Criadores como Andy Warhol e Richard Hamilton tinham uma visão totalmente diferenciada de outros artistas de movimentos precedentes. Eles não se colocavam em um pedestal, nem se achavam seres iluminados e superiores às pessoas comuns. Andy Warhol, que chamava seu ateliê de Fábrica, sempre se manteve imerso na sociedade e na cultura popular. Segundo Warhol "ser bom nos negócios é o mais fascinante tipo de arte ... Ganhar dinheiro é arte, trabalhar é arte, e bons negócios são a melhor arte" (McCarthy, 2001, p.26); "A produção de belas-artes de Hamilton, por sua vez, como de outros artistas pop, parecia autorizar o consumo de muitas mercadorias, incluindo-se a própria arte" (ibidem, p.27).

A Pop Art era praticamente o retrato de uma época em que tudo estava focado no consumo desenfreado. No seu enfoque publicitário, as obras do movimento mostravam com irreverência o universo socioeconômico do pós-guerra.

Os anos 50 também traziam novidades em relação aos novos materiais, desenvolvidos durante a Segunda Guerra Mundial. O kitsch jamais seria o mesmo depois do plástico, desde então a principal matéria-prima dos seus objetos. O vinil, o acrílico, o nylon e o PVC também são alguns dos novos materiais utilizados na indústria.

Os anos 60, a chamada "Idade do Espaço", trouxeram a inovação tecnológica, conseqüência da Guerra Fria, e todo o desejo de mudança da nova geração. Os olhos da indústria e do comércio voltaram-se para esses jovens consumidores que queriam, além de mudar o mundo, ter um estilo próprio. E que estilo. A década que mais olhou para o futuro tinha no design dos seus produtos tendências 'pop-futuristas' e espaciais. De roupas prateadas a televisões que lembravam capacetes espaciais, tudo remetia ao futuro.

As velhas idéias modernistas já não convenciam. Era hora de quebrar as amarras de um sistema tradicionalista e repressor. Surgia o multiculturalismo, a liberação sexual, a aceitação das diferenças, enfim, a pós-modernidade.

O neokitsch e o design, tanto gráfico quanto do produto, não passariam imunes a tantas transformações. A op art (arte óptica) estampava as minissaias, uma das maiores invenções da década, símbolo da liberação sexual da mulher. O movimento surgiu simultaneamente nos Estados Unidos e na Europa e fazia um jogo com a percepção óptica humana, usando efeitos visuais como sobreposição, movimento e interação do fundo com o foco principal.

Os motivos florais dos hippies também estamparam muitas peças neokitsch. E o psicodelismo? Com suas cores alucinantes, foi um dos movimentos pós-modernos mais influentes. A fosforecência das suas formas abstratas, que tinha sua linguagem visual baseada na art nouveau, no Oriente e nas alucinações causadas pelas drogas usadas pelos artistas, estava presente em capas de disco de bandas como Cream e Mutantes e cantores como Bob Dylan.

Os anos 70 chegaram com toda a purpurina. A moda 'disco' das sandálias plataforma com meia lurex, calça pantalona, globos espelhados, isso tudo, somado ao psicodelismo, ao punk e às plumas do glam rock, marcaram o estilo da década.

Os estilos passaram a ser cada vez mais combinados entre si nos anos que pensou-se serem os últimos em que o neokitsch imperaria. Ao contrário, o tempo mostrou que ele nunca esteve tão vivo e que não se extinguiria.

Os anos que se seguiram só vieram comprovar a imortalidade do kitsch. O mundo pósmoderno, multicultural e sem fronteiras promoveu nas décadas de 1980 e 1990 e nos anos iniciais do novo século a presença perpétua da atitude kitsch.

\section{Pedro Almodóvar}

O espanhol Pedro Almodóvar é um dos diretores mais autobiográficos do cinema. Ele tem sua história refletida em toda a sua obra, do primeiro dos seus curtas, na década de 1970, aos longas mais recentes. Seus trabalhos são o espelho do país onde nasceu, do amor e admiração por dona Francisca Caballero (sua mãe), dos colégios onde estudou, das suas preferências sexuais, das suas escolhas na vida.

Tomei a mim mesmo como referência, e isto é como colocar diante de si a pergunta: este é você ou não é? E na verdade não sei. Algumas das coisas que vieram à tona ao olhar para o meu próprio eu me dão um pouco de medo ... Você está fazendo experiências com seu próprio eu e isso pode ser doloroso e perigoso. É uma viagem psicológica muito perigosa, não por uma questão de vaidade, de descobrir coisas sobre você que não Ihe agradam; perigosa é a viagem em si ... Em todo esse processo eu fui cobaia em minhas próprias mãos. (Pedro Almodóvar, 1994) 


\section{Infodesıgn}

O kitsch se enquadra na própria vivência de Almodóvar. Ele está na sociedade espanhola, na sua profunda relação com a cor e na influência nítida da pop art em suas primeiras películas, muito bem representada pela mistura de elementos da cultura pop e por suas chicas que, assim como as de Andy Warhol, também foram inspiradas nas estrelas de Hollywood.

A atitude reina soberana nos seus dez primeiros longas. Santos católicos, melodrama, grandes paixões, personagens de cartoons e contos de fadas e objetos corriqueiros do consumo popular povoam os cenários almodovarianos não deixando ocultar o lado 'pop' e, acima de tudo, kitsch do diretor. No que chamamos de sua ' $1^{\text {a }}$ fase', que vai até 1993, com o filme Kika, o kitsch se faz presente em cada ambiente, figurino e maquiagem dos longas de Almodóvar: "O kitsch está presente em todos os meus filmes e é inseparável da prática religiosa. Ele protege o meu pudor e eu tenho muito pudor" (Almodóvar, 1994).

O kitsch está na extravagância das roupas e adereços, na maquiagem marcada por cores fortíssimas e traços extravagantes; no uso de texturas de animais, bolas e flores constantes; nos altares e quadros de imagens religiosas; nos bichos de pelúcia; nos eletrodomésticos e nos móveis.

As cores fortes, sobretudo primárias e secundárias, e um gosto peculiar pela complementaridade natural entre elas também são evidências do kitsch. A mãe do diretor, Francisca Caballero, vestiu luto desde que tinha 3 anos, por causa da morte de seu pai, até o nascimento de Pedro. A partir daí, ela nunca mais vestiu o preto. Almodóvar conta em entrevista que esse fato foi crucial na sua relação tão intensa com o cromatismo: "Depois de tantos anos de escuridão, minha mãe representa a vingança contra o negro. Eu decidi que minha vida estaria determinada pela cor, que se experimenta pelo excesso de cor".

Todos esses elementos coroaram Almodóvar como o 'Rei do Kitsch'. Como esquecer o 'Mambo Táxi' de Mulheres à beira de um ataque de nervos? Os assentos de pelúcia com textura de oncinha, todos aqueles penduricalhos e a figura hilária do taxista fazem do carro um dos melhores exemplos do kitsch nas suas películas:

Ao zombar do kitsch, o olhar de Almodóvar rompe a cortina que oculta a falsidade do kitsch da telenovela ou da publicidade e nos revela a crueza da verdade. A ironia desativa o kitsch, sem atacá-lo nem negá-lo; porque finalmente faz parte de uma maneira de ver e entender do homem de hoje no mundo todo.

(Santana apud Moreno, 1996, p.200)

\section{4. 'Rei do Kitsch'?}

Para identificar a real existência dos elementos do kitsch na obra de Almodóvar foi elaborado um modelo de análise baseado nas já citadas teorias desenvolvidas por Abraham Moles sobre a tipologia do kitsch.

Para esse modelo foram eleitas três tipologias estabelecidas por Moles. A primeira tipologia trata dos grupos de objetos. Ela define as relações entre eles, que podem ser classificadas em empilhamento, heterogeneidade, antifuncionalidade e autenticidade.

A segunda tipologia refere-se às formas elementares predominantes nos objetos kitsch: formas curvas, cores fortes, materiais disfarçados e ornamentação.

Finalmente, a terceira tipologia identifica os níveis opostos de abstração dos objetos pelas dualidades: religioso versus profano, familiar versus erótico, comum versus exótico e tradicional versus futurista.

Como amostra foram escolhidos os filmes Mulheres à beira de um ataque de nervos (Mujeres al borde de um ataque de nervios, 1987), Ata-me (¡Átame!, 1989) e Kika (Kika, 1993), eleitos por serem (ao nosso ver) os mais kitsch de toda a obra de Pedro Almodóvar. De cada película foram selecionados quatro frames e, em seguida, escolhidos cinco elementos predominantes, com o objetivo de detectar características do kitsch para comprovar sua forte presença na obra do diretor.

A aplicação do modelo de análise confirmou nos três filmes escolhidos a presença de elementos que caracterizam o kitsch.

Em linhas gerais, nos quatro frames analisados de cada película, os critérios de heterogeneidade, antifuncionalidade e autenticidade obtiveram $100 \%$ de ocorrências. A surpresa, no que diz respeito à tipologia dos grupos de objetos, relacionou-se ao fator empilhamento. Apesar de surgir em todos os frames analisados de Kika, o empilhamento não se mostrou tão comum nas cenas dos demais filmes. A película Mulheres à beira de um ataque de nervos teve $75 \%$ de incidência, e Ata-me menos ainda, $25 \%$, o que equivale a apenas um frame. O percentual total $(67 \%)$ mostra que o empilhamento, ao contrário dos outros fatores que comportam as relações dos 
objetos entre si, não surge com freqüência. Provavelmente isso aconteça porque o grande amontoado de coisas atrapalhe o andamento da cena, comprometendo a atuação e desviando a atenção do público.

Num segundo momento da investigação, as formas predominantes dos artigos escolhidos correspondiam às formas observadas no kitsch com maior incidência, de acordo com Moles.

As cores fortes e a ornamentação apareceram em $100 \%$ das situações, o que confirma, em primeiro lugar, a forte relação de Almodóvar com as cores, que parecem querer 'saltar' da tela. A grande presença da ornamentação também confirma o título de 'rei do kitsch' que o diretor recebeu na sua fase mais purpurinada.

As cores quentes, sobretudo os tons de vermelho, são particularidades inconfundíveis da assinatura de Almodóvar. Mas os vermelhos nunca estão sós. Geralmente aparecem em cena junto com os tons de azul e verde. O contraste entre as cores complementares é uma marca registrada da obra do espanhol. Por isso, embora as cores quentes sejam predominantes, as cores frias surgem também em grande quantidade nos frames. Já a luminosidade dos objetos, previsivelmente, na maioria deles, é positiva: $67 \%$. Os objetos opacos - especialmente pelúcias e outros tecidos - totalizam $33 \%$.

E as formas curvas predominam (75\%). Apesar da grande brincadeira que Almodóvar faz com as formas orgânicas e geométricas, estas últimas aparecem bem menos na tela. Por falar no jogo entre elementos geométricos e orgânicos, o filme que mais faz uso dessa combinação é Kika, que apresentou percentuais iguais (50\%) para ambos.

Quanto aos materiais disfarçados, a incidência total foi de $75 \%$. Os objetos que predominaram nesta classificação geralmente simularam folhas e flores (com tecido ou plástico) e pele de animas (com pelúcia). Em menor proporção, surgiram objetos pintados de dourado (simulando ouro). A película que continha mais artigos com material dissimulado foi Mulheres à beira de um ataque de nervos, com o percentual máximo.

Os dados obtidos com o estudo sobre os níveis de abstração opostos, contidos nos grupos de objetos, mostram que, com $75 \%$ do total, as três películas de Pedro Almodóvar apresentam essas propriedades em alto grau. A justificativa para os números está na aparição de muitos objetos comuns ao uso popular, em combinação com artigos excêntricos (exóticos) que têm uma relação profunda com o comportamento dos personagens e dão veracidade à história.

$\mathrm{Na}$ grande maioria dos critérios propostos, os números que indicam os objetos escolhidos como verdadeiramente kitsch foram praticamente unânimes. Considerando o contexto dos quadros escolhidos, ou seja, os três filmes mais kitsch de toda a obra de Almodóvar (ao nosso ver), os resultados obtidos confirmaram o óbvio: o título de 'rei do kitsch' não foi gratuito.

Ainda sobre a análise, o modelo foi bastante satisfatório, de grande objetividade e eficiência para a pesquisa e, além disso, apontou com exatidão as propriedades presentes e ausentes do kitsch. Contudo, a sua maior qualidade é que ele não se restringe unicamente, ao suporte cinematográfico. Pode ser aplicado a impressos, produtos, à web e ao vídeo, sem problema algum, por não ter qualquer referência sobre eles. O modelo trata, exclusiva e propositadamente, das propriedades estéticas do kitsch, já que sinaliza para a continuidade da investigação de tais características em outros meios.
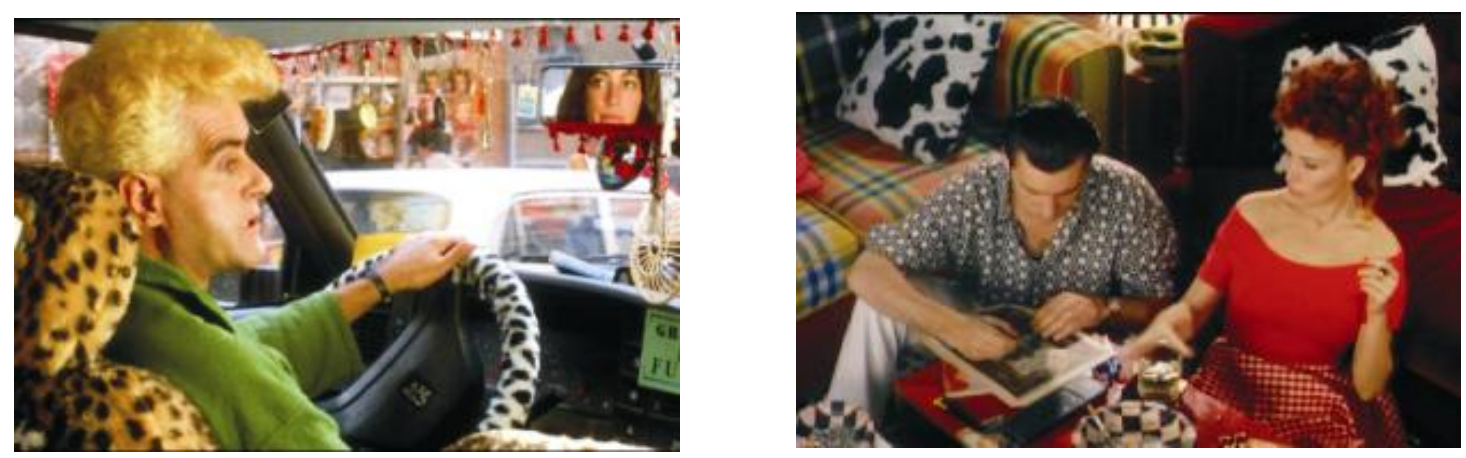


\section{Inf0desıgn}

Figura 3. Frame de Kika

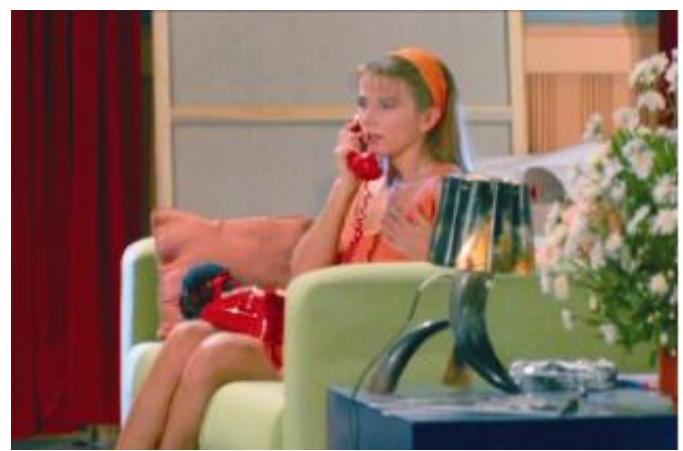

\section{Considerações finais}

Este artigo tentou desmistificar o significado do kitsch e sua influência estética desde o surgimento até os dias atuais, sobretudo, na obra de Pedro Almodóvar. Enquanto o universo da cultura kitsch era desvendado, um campo de estudo encantador ia sendo descoberto. $O$ que antes parecia uma palavra vazia, geralmente usada com tom depreciativo, agora define um mundo fantástico criado pela autenticidade do gosto popular.

\section{Referências}

\section{Almodóvar}

Balogh, Anna Maria. Colagens em Movimento. In: Peñuela Cañizal, E. (Org.) Urdiduras de sigilos. São Paulo: Annablume; ECA-USP, 1996. 352p.

Folha Online. Disponível em: http://www1.folha.uol.com.br/folha/ilustrada/ult90u44134.shtml. Acesso em: 07.01.2005.

La jornada. Disponível em: http://www.jornada.unam.mx/1998/mar98/980313/esp-almodovar.html. Acesso em: 31.12.2004.

Pedro Almodóvar. Disponível em: http://www.cinepop.com.br/perfil/pedro_almodovar.htm. Acesso em: 07.12.2004; http://www.imdb.com/find?q=Almodovar;tt=on; $n m=o n ; m x=20$. Acesso em: 07.12.2004; http://pt.wikipedia.org/wiki/Pedro_Almodovar. Acesso em: 14.09.2004.

Pedro Almodóvar. http://clubcultura.com/clubcine/clubcineastas/almodovar/esp/premios.htm. Acesso em: 07.12.2004. (website oficial)

Peñuela Cañizal, Eduardo. A corrosão do relato falocêntrico no primeiro longa de Almodóvar. In: Peñuela Cañizal, E. (Org.) Urdiduras de sigilos, 1996. 352p.

Santana, Gelson. Espelho-Esfinge. In: Urdiduras de sigilos. In: Peñuela Cañizal, E. (Org.) Urdiduras de sigilos, 1996. 352p.

\section{Kitsch}

Eco, Umberto. Apocalípticos e integrados. São Paulo: Perspectiva (Coleção Debates), 1979. 6.ed. 385p.

O Estado de S. Paulo. Disponível em: http://www.estadao.com.br. Acesso em: 07.02.2005.

Gillilan, Lesley. Kitsch Deluxe. London: Mitchell Beazley, 2003. 144p.

Harvey, David. A condição pós-moderna: uma pesquisa sobre as origens e mudanças sociais. São Paulo: Loyola, 2000

Heartney, Eleanor. Pós-modernismo. São Paulo: Cosac \& Naify, 2001. 80p.

Kitsch. Disponível em: http://www.saplei.eesc.usp.br/tgi/texto_carson_kitsch.doc. Acesso em 01.06.2004. 
Lipovetsky, Gilles. O império do efêmero: a moda e seu destino nas sociedades modernas. São

Paulo: Companhia das Letras, 1989. 294p.

MacCarthy, David. Arte pop. Trad. Otacílio Nunes. São Paulo: Cosac \& Naify, 2001. 80p.

Moles, Abraham. O kitsch. Trad. Sérgio Miceli. São Paulo: Perspectiva (Coleção Debates), 1971. 5.ed. 232p.

Olalquiaga, Celeste. Megalópolis. Caracas: Monte Ávila, 1993. 144p.

Tambini, Michael. O design do século. São Paulo: Ática, 1999. 2.ed. 288p.

\section{Sobre os autores}

\section{Hallina Beltrão}

Graduada em Design pela Universidade Federal de Pernambuco no ano de 2005, quando ganhou o Prêmio Gastão de Holanda por ter realizado um dos melhores projetos de graduação de 2004,"Eu kitsch", que foi incorporado ao acervo do Centro de Documentación Pedro Almodóvar, sediado na Universidad Castilla - La Mancha, Espanha.

hallsbeltrao@hotmail.com

\section{Hans Waechter}

Graduado em Desenho Industrial I Programação Visual pela Universidade Federal de Pernambuco (1980), com especialização em Comunicación Audiovisual pela Universidad Autónoma de Barcelona (1999), mestrado (2000) e doutorado (2004) em Comunicación Audiovisual y Publicidad pela Universidad Autónoma de Barcelona. Atualmente é Professor Adjunto 1 da Universidade Federal de Pernambuco.

hnwaechter@terra.com.br 